\title{
Estimating Latent Heat Flux from a Vineyard using Scintillometry
}

\author{
Alan E. Green ${ }^{1,{ }^{*}}$, Steve R. Green ${ }^{1}$, Mark S. Astill ${ }^{1}$ and Horst W. Caspari ${ }^{1}$
}

(Manuscript received 26 November 1999, in final form 28 March 2000)

\begin{abstract}
The combination of a near-infrared and a microwave scintillometer were used to estimate the line-averaged, latent heat flux density $\left(\lambda E_{s}\right)$ from a well-irrigated, vineyard valley during summer. The $2 \mathrm{~km}$ scintillometer beam passed over the valley floor at a height (z) of $30 \mathrm{~m}$. Eddy covariance towers instrumented at $3 \mathrm{~m}$ above the valley surface provided an independent check of vineyard evaporation. A formula for free convective $\lambda E_{s}$ compared favourably to the eddy covariance values, $\lambda E_{e}$ at low wind speeds and under clear skies. As the convective boundary layer (CBL) developed and passed through the scintillometer beam it caused additional scintillations, in which case $\lambda \mathbf{E}_{s} \gg \lambda \mathbf{E}_{\mathrm{e}}$. During unstable conditions the comparisons were in close agreement. However $\lambda \mathbf{E}_{\mathrm{s}}$ tended to overestimate $\lambda \mathbf{E}_{\mathrm{e}}$ as the wind speed increased. For near-neutral conditions the scintillometer gave unrealistically large values of $\lambda \mathbf{E}_{s}$. The additional scintillations originated from the strong entrainment of advected dry and warm air into the newly formed surface boundary layer.

During calm overcast days, cold days and during the early morning periods when the surface fluxes were small, the signal strength of the infrared scintillometer approached the system noise.
\end{abstract}

(Keywords: Scintillation, Line-averaged, Latent heat flux, Large-scale)

\section{INTRODUCTION}

Over the last ten years several experiments have used a combination of a microwave and near-infrared scintillometer to determine the line-averaged fluxes of the sensible heat $\mathrm{H}_{\mathrm{s}}(\mathrm{W}$ $\left.\mathrm{m}^{-2}\right)$ and the latent heat $\lambda \mathrm{E}_{\mathrm{s}}\left(\mathrm{W} \mathrm{m}^{-2}\right)$, directly above the Earth's surface. Notable is the experiment of Hill et al. (1988) who used scintillometers operating at millimeter and micrometer

\footnotetext{
${ }^{1}$ The Horticultural Research Institute of New Zealand, Kerikeri Research Centre, Kerikeri, Bay of Islands, New Zealand

* Corresponding author address: Dr. Alan E. Green, The Horticultural Research Institute of New Zealand, Kerikeri Research Centre, P. O. Box 23, Kerikeri, Bay of Islands, New Zealand

E-mail: agreen@hort.cri.nz
} 
wavelengths. They were the first to outline the methodology for determining $\mathrm{H}_{s}$ and $\lambda \mathrm{E}_{\mathrm{s}}$ and produce what Hill described as 'a reasonable agreement with those values from micrometeorological measurements'. The next recorded experiment using multiple scintillometers was Green et al. (1999) who found $\mathrm{H}_{s}$ and $\lambda \mathrm{E}_{\mathrm{s}}$ compared favorably to eddy covariance measurements made at the midpoint of the scintillometer transect. This latter experiment confirmed that the recently designed microwave scintillometer was operational and sensitive to inertial sized eddies of heat and water vapor. This research also highlighted the effect of line-averaged, low frequency humidity fluctuations and their detrimental effect on the scintillometer signals. In both these experiments the surface was flat, expansive and homogeneous in surface coverage with the scintillometer beam close to the canopy $(\mathrm{z}<10 \mathrm{~m})$.

There are provisos for the scintillometer method because it is indirect in its approach, relying upon similarity theory to scale the temperature structure parameter, $\mathrm{C}_{\mathrm{T}}^{2}\left(\mathrm{~K}^{2} \mathrm{~m}^{-2 / 3}\right)$ and the humidity structure parameter, $\mathrm{C}_{\mathrm{Q}}^{2}\left(\left[\mathrm{~g} \mathrm{~m}^{-3}\right]^{2} \mathrm{~m}^{-2 / 3}\right)$ as functions of atmospheric stability. In practice, these parameters are first calculated from the scintillometer signals then incorporated into similarity functions to determine $\mathrm{H}_{\mathrm{s}}$ and $\lambda \mathrm{E}_{\mathrm{s}}$. To satisfy the prerequisites of similarity theory, scintillometer experiments should be conducted over a flat and homogeneous landscape under a relatively stationary atmosphere. This satisfies the empirical linking (albeit at times tenuous) of the scintillometer beam-intensity perturbations with the surface generated eddies of heat and moisture.

If there is to be an acceptance of the scintillometer method, comprehensive experimental verification and testing over a variety of terrain and atmospheric conditions is mandatory. It is our intent in this paper to contribute an improved understanding of the scintillometer method from initial experience gained with this scintillometer combination (Green et al., 1999). We present here results using a microwave and near-infrared scintillometer propagating across a vineyard valley. Our approach is somewhat different than other close to the canopy scintillometer experiments. A vineyard has been studied previously using an near-infrared scintillometer (De Bruin et al., 1995) however the scintillometer beam was very close to the canopy $(\mathrm{z}=3.3 \mathrm{~m})$ and the soil-plant conditions were dry. Here we examine the scintillometer capability to measure the surface evaporation across an irrigated valley and at a beam height much greater than previously attempted for this two-scintillometer combination. Operating at height is necessary to cover the large distances (up to $10 \mathrm{~km}$ ). The surrounding farmland was drought stricken. We suspected the contrast in soil-water conditions would cause additional scintillations if dry air advected into the valley. The scintillometers were installed at $z=30 \mathrm{~m}$ above the valley floor by placing them on opposing and exposed ridges (see Fig. 1). Within the vineyard at two locations eddy covariance instruments monitored $H_{e}$ and $\lambda E_{e}$. These measurements provided a measure of the vineyard energy balance and a benchmark for the scintillometer determined fluxes. The valley floor had no significant undulations and the canopy was of a consistent roughness about the center of the scintillometer beam (maximum scintillometer weighting). Based on past experience (Green et al., 1999) it was believed possible to estimate half hourly $\lambda E_{s}$. The preferred wind direction was from the NW, because this was the wind that blew up the valley and across substantial grape planting before intersecting the scintillometer beam. If the wind blew into the valley from across the surrounding hill-sides 
this could adversely effect the scintillometer performance and $\lambda \mathrm{E}_{\mathrm{s}}$ was treated with scepticism.

\section{THEORY}

Scintillometers provide a wavelength-dependent, line-averaged measurement of the refractive-index structure parameter, $C_{n}^{2}\left(m^{-2 / 3}\right)$. Embedded within each value of $C_{n}^{2}$ reside the weighted spatial effects of temperature and humidity fluctuations that have affected the scintillometer beam along its entirety. Each received scintillometer signal is time integrated within a bandwidth that encompasses the inertial subrange of turbulent eddies. These conditioned scintillometer signals provide the first step in determining $\mathrm{H}_{\mathrm{s}}$ and $\lambda \mathrm{E}_{\mathrm{s}}$.

\subsection{Structure Parameters $C_{T}^{2}$ and $C_{Q}^{2}$}

Through assuming these structure parameters obey Monin-Obukhov Similarity Theory (MOST) Hill et al. (1988), provide the values of $\mathrm{C}_{\mathrm{T}}^{2}$ and $\mathrm{C}_{\mathrm{Q}}^{2}$ obtained for a dual scintillometer operating at microwave and near-infrared wavelengths (denoted by subscripts ${ }_{m}$ and ${ }_{i}$ respectively) as,

$$
\begin{aligned}
& \mathrm{C}_{\mathrm{Q}}^{2}=\left[\mathrm{A}_{\mathrm{T}, \mathrm{m}}^{2} \mathrm{C}_{\mathrm{n}, \mathrm{i}}^{2}+\mathrm{A}_{\mathrm{T}, \mathrm{i}}^{2} \mathrm{C}_{\mathrm{n}, \mathrm{m}}^{2}+2 \mathrm{SA}_{\mathrm{T}, \mathrm{m}} \mathrm{A}_{\mathrm{T}, \mathrm{i}} \sqrt{\mathrm{C}_{\mathrm{n}, \mathrm{m}}^{2} \mathrm{C}_{\mathrm{n}, \mathrm{i}}^{2}}\right] /(\mathrm{TD})^{2}, \\
& \mathrm{C}_{\mathrm{T}}^{2}=\left[\mathrm{A}_{\mathrm{Q}, \mathrm{m}}^{2} \mathrm{C}_{\mathrm{n}, \mathrm{i}}^{2}+\mathrm{A}_{\mathrm{Q}, \mathrm{i}}^{2} \mathrm{C}_{\mathrm{n}, \mathrm{m}}^{2}+2 \mathrm{SA}_{\mathrm{Q}, \mathrm{m}} \mathrm{A}_{\mathrm{Q}, \mathrm{i}} \sqrt{\mathrm{C}_{\mathrm{n}, \mathrm{m}}^{2} \mathrm{C}_{\mathrm{n}, \mathrm{i}}^{2}}\right] /(\mathrm{QD})^{2},
\end{aligned}
$$

$\mathrm{A}_{\mathrm{T}}^{2}$ and $\mathrm{A}_{\mathrm{Q}}^{2}$ are parameters (Hill et al., 1980) that are influenced by the operating wavelength of the scintillometer, absolute temperature $\mathrm{T}(\mathrm{K})$, pressure $\mathrm{P}\left(\mathrm{N} \mathrm{m}^{-2}\right)$ and humidity $\mathrm{Q}\left(\mathrm{g} \mathrm{m}^{-3}\right)$.

The factor D expands to,

$$
\mathrm{D}=\left[\mathrm{A}_{\mathrm{T}, \mathrm{m}} \mathrm{A}_{\mathrm{Q}, \mathrm{i}}-\mathrm{A}_{\mathrm{T}, \mathrm{i}} \mathrm{A}_{\mathrm{Q}, \mathrm{m}}\right] / \mathrm{TQ}
$$

One significant consequence of MOST is that $\mathrm{S}$, the T-Q correlation coefficient takes a value of +1 for unstable conditions (Hill, 1989). Such a correlation has not always been observed in scintillation experiments. For instance Kohsiek (1982) found an average S of 0.75 while Hill et al. (1988) found $S$ to be much closer to unity $(S=0.99)$.

\subsection{Sensible and Latent Heat Flux Densities}

Our primary interest in scintillometers is determining line-averaged values of $\mathrm{H}_{\mathrm{s}}$ and $\lambda \mathrm{E}_{\mathrm{s}}$ at kilometer scales. To infer these fluxes across large areas scintillation measurements must be made over long horizontal paths. In this experiment the scintillometer averages the scintillometer signals over a horizontal distance of $2 \mathrm{~km} . \lambda \mathrm{E}_{\mathrm{s}}$ is our main surface flux of interest 
because of its potential for irrigation scheduling. Operating over such distances or greater is acceptable provided the scintillometer pathlength is a small fraction of the boundary layer height. For instance Kohsiek (1985) operated a $\mathrm{CO}_{2}$ laser scintillometer over $5.9 \mathrm{~km}$ and $\mathrm{z}=$ $40 \mathrm{~m}$. At such heights slight non-uniformity in the surface maybe from ditches or roads, cloud cover or canopy cover are blended with the surrounding surfaces if there is some mechanical mixing of the boundary layer. Because this scintillometer process is one of line-averaging, a single spatial anomaly at the surface would need to cause a very significant difference in surface flux to produce a measurable signal change at the scintillometer receiver. In such cases it would be unwise to select an experimental site that wasn't fairly uniform. The scintillation method can be considered a form of low-pass filtering whereby small spatial and temporal changes are smoothed by the average signal. Further, as the weighting function of the scintillometer method is symmetrically bell shaped, the scintillometer can be positioned to minimise the effect of any significant change in surface conditions from the normal cover underlying the beam.

Currently MOST provides the only framework for indirectly predicting $\mathrm{H}_{\mathrm{s}}$ and $\lambda \mathrm{E}_{\mathrm{s}}$ from $\mathrm{C}_{\mathrm{T}}^{2}$ and $\mathrm{C}_{\mathrm{Q}}^{2}$. As has been previously discussed the ideal situation for such experiments is a flat and homogeneous site having a stationary atmosphere. Such was the case in the Kansas Plain Experiment from where the original MOST algorithms were derived (Wyngaard, 1973). In this experiment we assumed MOST was applicable in the vineyard and $\mathrm{C}_{\mathrm{Q}}^{2}$ and $\mathrm{C}_{\mathrm{T}}^{2}$ would scale to the scintillometer beam height as functions of atmospheric stability $\left(\mathrm{z} / \mathrm{L}_{\mathrm{o}}\right)$.

We use the empirical scaling relationship of Hill et al. (1988) for unstable conditions,

$$
\mathrm{g}\left(\frac{\mathrm{z}}{\mathrm{L}_{0}}\right)=4.9\left(1-7\left|\frac{\mathrm{z}}{\mathrm{L}_{0}}\right|\right)^{-2 / 3}=\frac{\mathrm{C}_{\mathrm{Q}}^{2} \mathrm{z}^{2 / 3}}{\mathrm{Q}_{*}^{2}}=\frac{\mathrm{C}_{\mathrm{T}}^{2} \mathrm{z}^{2 / 3}}{\mathrm{~T}_{*}^{2}} \quad, \mathrm{z} / \mathrm{Lo}<0
$$

$L_{\circ}(m)$ is the buoyancy length scale, which includes a correction for humidity fluctuations and is defined by,

$$
\mathrm{L}_{0}=-\frac{\mathrm{u}^{2}{ }_{*} \mathrm{~T}}{\mathrm{gKT}_{*}(1+0.07 / \beta)}
$$

$\kappa=0.4$ is von Karman's constant, $T_{*}(K)$ is the temperature scaling parameter, $g=9.81 \mathrm{~m}$ $\mathrm{s}^{-2}$ is gravitational acceleration and $\beta=\mathrm{H}_{\mathrm{s}} / \lambda \mathrm{E}_{\mathrm{s}}$ we have called the line-averaged Bowenratio. Kohsiek (1982) notes that $\beta$ is proportional to the ratio $C_{\tau} / C_{Q}$ which are two of the structure parameters derived from this experimental scintillometer. The humidity scaling parameter $\mathrm{Q}_{*}\left(\mathrm{~g} \mathrm{~m}^{-3}\right)$ and the velocity scale $\mathrm{u}_{*}\left(\mathrm{~m} \mathrm{~s}^{-1}\right)$ combine to give a value for $\lambda \mathrm{E}_{\mathrm{s}}$ as,

$$
\lambda \mathrm{E}_{\mathrm{s}}=\mathrm{L}_{\mathrm{v}} \mathrm{u}_{*} \mathrm{Q}_{*}
$$


The latent heat of vaporisation of water $\mathrm{L}_{\mathrm{v}}$ is taken here as $2.45 \times 10^{3} \mathrm{~kJ} \mathrm{~kg}^{-1}$.

Obtaining a reliable line-averaged $\mathrm{u}_{*}$ for inclusion in (2.6) is difficult to achieve and other options are favoured. Over a homogeneous surface a line-averaged $u_{*}$ is preferred to that obtained from either an eddy covariance measurement or that estimated from the windspeed profile and a surface roughness measurement. Neither of the latter approaches will spatial average $u_{*}$ at the length scale of the scintillometer transect. It is impractical to measure $u_{*}$ at the scintillometer beam height of $30 \mathrm{~m}$ and position of maximum signal weighting (the midpoint of the beam). Instead, conventional meteorological instruments placed at $\mathrm{z}=3 \mathrm{~m}$ estimate $\mathrm{u}_{*}$ which is then taken as being equivalent at $\mathrm{z}=60 \mathrm{~m}$ because a constant flux layer is assumed.

For near-neutral conditions, typically characterized by overcast skies, strong surface winds and low values for surface fluxes, $\left(\mathrm{z} / \mathrm{L}_{0}\right)$ approaches zero as mechanical turbulence dominates. The wind profile is logarithmic with $\mathrm{z}$ and $\mathrm{u}_{*}$ can be determined from an average windspeed $\mathrm{u}_{\mathrm{c}}$ $\left(\mathrm{m} \mathrm{s}^{-1}\right)$ at $\mathrm{z}=3 \mathrm{~m}$, the canopy displacement height $\mathrm{d}(\mathrm{m})$ and surface roughness $\mathrm{z}_{\mathrm{o}}(\mathrm{m})$ using,

$$
\mathbf{u}_{*}=\frac{\kappa u_{c}}{\ln \left(z-d / z_{0}\right)}
$$

An empirical calculation of $z_{o}$ is made assuming $z_{o} / h_{c}=0.13$ and $d / h_{c}=0.7$ (Sene, 1994). This requires an estimate of the average canopy height, $h_{c}(m)$. Deviation from the log-law increases for unstable conditions requiring a modification of (2.7) to become,

$$
u_{*}=\frac{\mathrm{ku}_{\mathrm{c}}}{\ln \left(\mathrm{z}-\mathrm{d} / \mathrm{z}_{0}\right)-\Psi\left(\mathrm{z} / \mathrm{L}_{0}\right)}
$$

The full expression for the function $\Psi\left(\mathrm{z} / \mathrm{L}_{0}\right)$ can be found in Panofsky and Dutton (1984). An iterative solution to (2.8) is obtained by first assuming an initial value for $\left(\mathrm{z} / \mathrm{L}_{0}\right)$ then calculating $u^{*}$. From $(2.5)$ a new $\left(z / L_{0}\right)$ is determined and substituted into $(2.8)$, the process repeating until convergence. In the author's experience this procedure is fairly robust, requiring on average, just three to four iterations to complete.

For a very unstable atmosphere, the free convective situation, when $\left(z \mathrm{~L}_{\mathrm{o}}\right)<-1$, mechanical mixing is not significant permitting a simplification of (2.4) using the prior the expressions for $\mathrm{L}_{\mathrm{o}}$ and $\lambda \mathrm{E}_{\mathrm{s}}$. This rearrangement expresses $\mathrm{C}_{\mathrm{Q}}^{2}$ as,

$$
\mathrm{C}_{\mathrm{Q}}^{2}=2.5\left(\frac{\lambda \mathrm{E}_{\mathrm{s}}}{\mathrm{L}_{\mathrm{v}}}\right)^{4 / 3} \mathrm{z}^{-4 / 3}\left(\frac{\mathrm{TQ}_{*}}{\mathrm{gT}_{*}}\right)^{2 / 3} .
$$

From (2.9) there is a decrease of $\mathrm{C}_{\mathrm{Q}}^{2}$ with height. In reality this is observed as a rapidly diminishing scintillometer signal. Scintillometers are placed at greater heights to reduce the risk of signal saturation and to obtain greater scales of spatial integration. In so doing the 
resolution of the scintillometer may be compromised.

Continuing with our derivation of $\lambda \mathrm{E}_{\mathrm{s}}$ under free convection, from (2.4),

$$
\frac{\mathrm{Q}_{*}}{\mathrm{~T}_{*}}=\frac{\mathrm{C}_{\mathrm{Q}}}{\mathrm{C}_{\mathrm{T}}} .
$$

By the substitution of (2.10) into (2.9),

$$
\lambda \mathrm{E}_{\mathrm{s}}=\mathrm{L}_{\mathrm{v}} \mathrm{z}\left(\frac{\mathrm{C}_{\mathrm{Q}}^{2}}{2.5}\right)^{3 / 4}\left(\frac{\mathrm{gC}_{\mathrm{T}}}{\mathrm{TC}_{\mathrm{Q}}}\right)^{1 / 2}
$$

This is a similar result to the free convective form given by Hill et al. (1988). Note that both $\mathrm{C}_{\mathrm{T}}$ and $\mathrm{C}_{\mathrm{Q}}$ are needed to estimate $\lambda \mathrm{E}_{\mathrm{s}}$ and so the technique requires at least two different wavelength scintillometers. In contrast the free convective, sensible heat flux only requires a value for $\mathrm{C}_{\mathrm{T}}$ which can be provided by a single near-infrared scintillometer (Panofsky and Dutton, 1984).

\section{EXPERIMENTAL}

\subsection{Site Description and Instrumentation}

The Brancott Estate situated in the fluvial Fairhall Valley at the foothills of the Southern Ranges is found on the outskirts of Blenheim (Marlborough region, South Island of New Zealand). The Estate was chosen as the experimental site, being one of the largest vineyards in this country encompassing some 240 ha of vines stretching across the valley floor and bounded by low hills (schematic Fig. 1). These hillsides provided a convenient solution to mounting the scintillometers sufficiently high so the beams could see the valley-floor and line-average the vineyard $\lambda \mathrm{E}_{\mathrm{s}}$. Using a laser theodolite the scintillometer transect was established as 1,969 $\mathrm{m}$ at an average height of $30.3 \mathrm{~m}$ above the valley floor. The grade was 1:248 from the transmitter end on the hillside above the dry Fairhall riverbed to the receiver end, 'Rob's Knob'. For the purposes of this experiment the scintillometer beam was treated as parallel to the ground surface. The scintillometer beam crossed the central portion of the vineyard in an $\mathrm{EW}$ direction from transmitter to receiver. The preferred wind direction was from the NW because it was from this direction that the wind blew up the valley and across the irrigated grapes ( $\mathrm{a}$ fetch of more than one kilometer) before intersecting the scintillometer beam. Downwind of the vineyard were further grape plantings (Fairhall Estate) but to the NE was the beginning of a dry scrub-land interspersed with a barren surface (local civilian and military airport) and some scattered olive plantings. This surrounding drier farming terrain then extended many kilometers to the base of the Nelson foothills (Richmond Range) having more 
vineyards on either side of the distant Wairau River. Because of a prolonged drought the irrigated Brancott Estate was for all practical purposes an oasis.

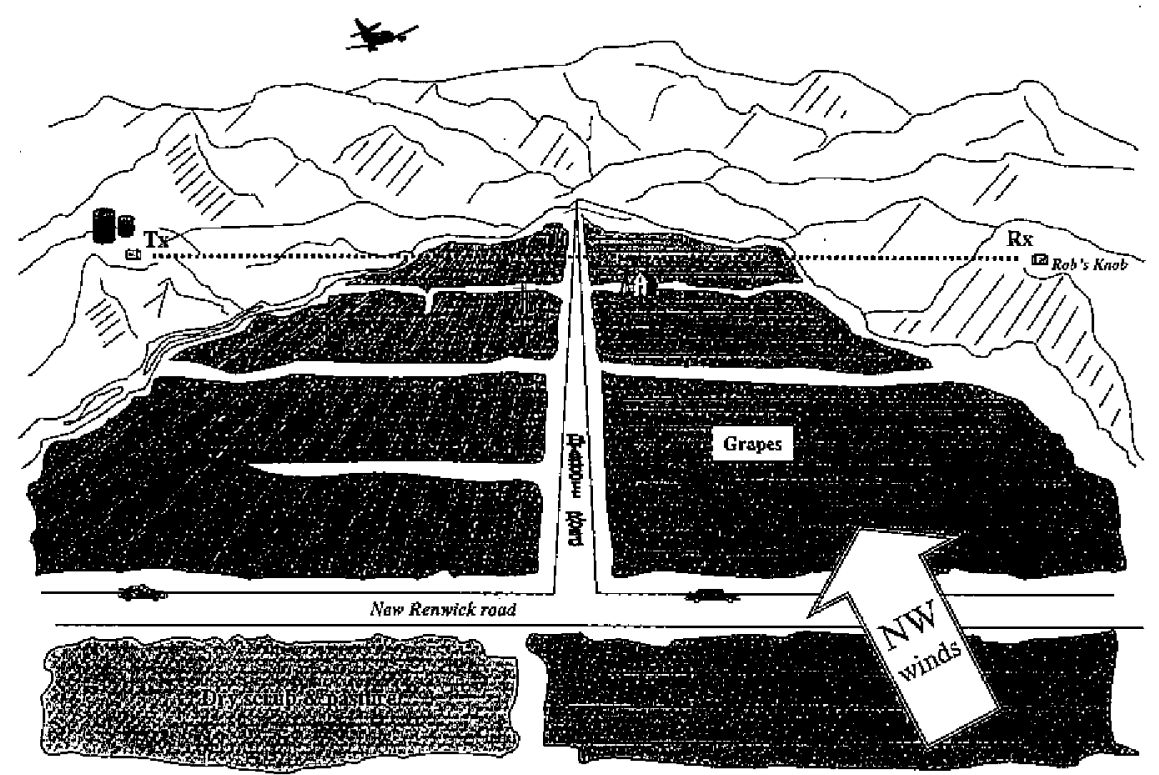

Fig. 1. A simplified schematic of the Brancott Valley showing the positions of the scintillometer and eddy covariance instruments.

The scintillometers were the same microwave $(1.1 \mathrm{~cm}$ wavelength) and near-infrared $(0.94$ $\mu \mathrm{m}$ wavelength) types as described by Green et al. (1999) and were mounted on short $1 \mathrm{~m}$ towers, themselves cemented into concrete bases at either end of the scintillometer transect. A plywood cover was built around each scintillometer to protect against wind vibration and the weather. At a later date, clear acrylic covers were added across the front openings as it was suspected the wind shear on the microwave dishes could cause unwanted mechanical scintillations. Acrylic is transparent at the scintillometer wavelengths. Following this experiment the scintillometers are now permanently housed in $1 \mathrm{~m}^{3}$ aluminium cubes with portable power systems and telemetry capability. This new construction greatly simplifies installation and is ideal for transportation and weatherproofing.

The Brancott Road running NS separated the Estate into eastern and western sections characterized by the grape-rows orientated NS on the eastern side and EW on the western side. In most cases the vines were planted $1.8 \mathrm{~m}$ apart in rows spaced at $3 \mathrm{~m}$ but planting age varied from 1 through to 25 years. The vines were trellised and $h_{c}$ was estimated as $1.5 \mathrm{~m}$, though some vines at the centre of the scintillometer beam were $2 \mathrm{~m}$ in height. The eastern side was planted in predominantly the Sauvignon Blanc variety with the canopy touching the ground. In comparison the vines on the western side were sparser and were pruned below $1 \mathrm{~m}$. The vineyard relied on irrigation to meet the water requirements with all vines receiving water via drip emitters. In contrast the inter-rows were dry and devoid of plant cover due to the enduring 
drought.

Two, 3 meter high, open-lattice towers were instrumented with rapid response 1-D sonic anemometer-thermometers and krypton hygrometers. Half-hourly values of $\lambda \mathrm{E}_{\mathrm{e}}$ and $\mathrm{H}_{\mathrm{c}}$ were calculated using the eddy covariance technique. Other slower sensors included sensitive cup anemometers, a net radiometer $\mathrm{R}_{\mathrm{n}}\left(\mathrm{W} \mathrm{m}^{-2}\right)$ and a combination temperature-relative humidity sensor. One tower was placed in the mature canopy on the eastern side almost directly under the centre of the scintillometer beams (designated the road site) and the other tower near to the Fairhall river and the much younger vines (the river site). Wind speed, temperature and the relative humidity were also recorded by data-loggers on Rob's Knob.

\subsection{Weather Conditions and Data Collection}

The experiment started in late summer, February 1998, during an exweme drought. There had been no significant rainfall in the Marlborough region during the previous winter-spring period. The surrounding hillsides and pastures were brown and dry with little if any growth. In contrast, the canopy of the vineyard was green and lush. Data collection first began on the afternoon of the 21st February (day of the year, D51) and was continuous for the next three days until the monthly average rainfall $(\sim 35 \mathrm{~mm})$ was experienced over the intervening days, D54 and D55. As the ground was baked hard very little of the rain penetrated the surface soil and most disappeared as runoff. Throughout days D51, D52 and D53 strong winds, mainly N - NW drove up the valley and through the scintillometer beam. Days D52 and D53 were overcast. These days had relatively low $\mathrm{H}_{\mathrm{e}}$ and $\lambda \mathrm{E}_{\mathrm{e}}$. By day D56 the rain had stopped and the sky was clear and the early morning winds were a cold SW blowing across the surrounding hills and through the scintillometer beam. In the afternoon the wind direction shifted around to the NE and was accompanied by intermittent cloud cover and an increasing air temperature. Day D57 had a clear sky with low windspeeds in the morning. By the early afternoon of D57 the windspeed had increased from a northerly direction. D58 started with a brilliantly clear morning which quickly degenerated into overcast conditions with SW wind. The final day of the experiment, D59, began the morning with strong SW winds and overcast skies followed by rain in the late afternoon.

Data from the eddy covariance and the scintillometer instruments was recorded using Campbell Scientific Inc. 21x micro-loggers programmed for 10 minute and half-hour averages. The data was retrieved daily by portable computer and analysed using a software spreadsheet. Supporting micrometeorological data were recorded using a standard met station located beside the eddy covariance instruments.

\section{RESULTS AND DISCUSSION}

\subsection{Near-neutral and Advective Conditions}

Day D51 had a clear sky with strong N-NW winds. In contrast days D52 and D53 were characterized by overcast skies but still with strong N-NW winds (see Fig. 2) that blew up the 
valley almost perpendicular to the scintillometer beam. For instance at $1200 \mathrm{hrs}$ the windspeed at $30 \mathrm{~m}$ was estimated to be $u_{c 30 m} \sim 24 \mathrm{~m} \mathrm{~s}^{-1}$. The calculation of $u_{c 30 m}$ assumed a logarithmic wind profile under near-neutral conditions. Subsequent calculations of $\mathrm{u}_{*}$ at $\mathrm{z}=3 \mathrm{~m}$ were taken as the same value at $\mathrm{z}=30 \mathrm{~m}$.

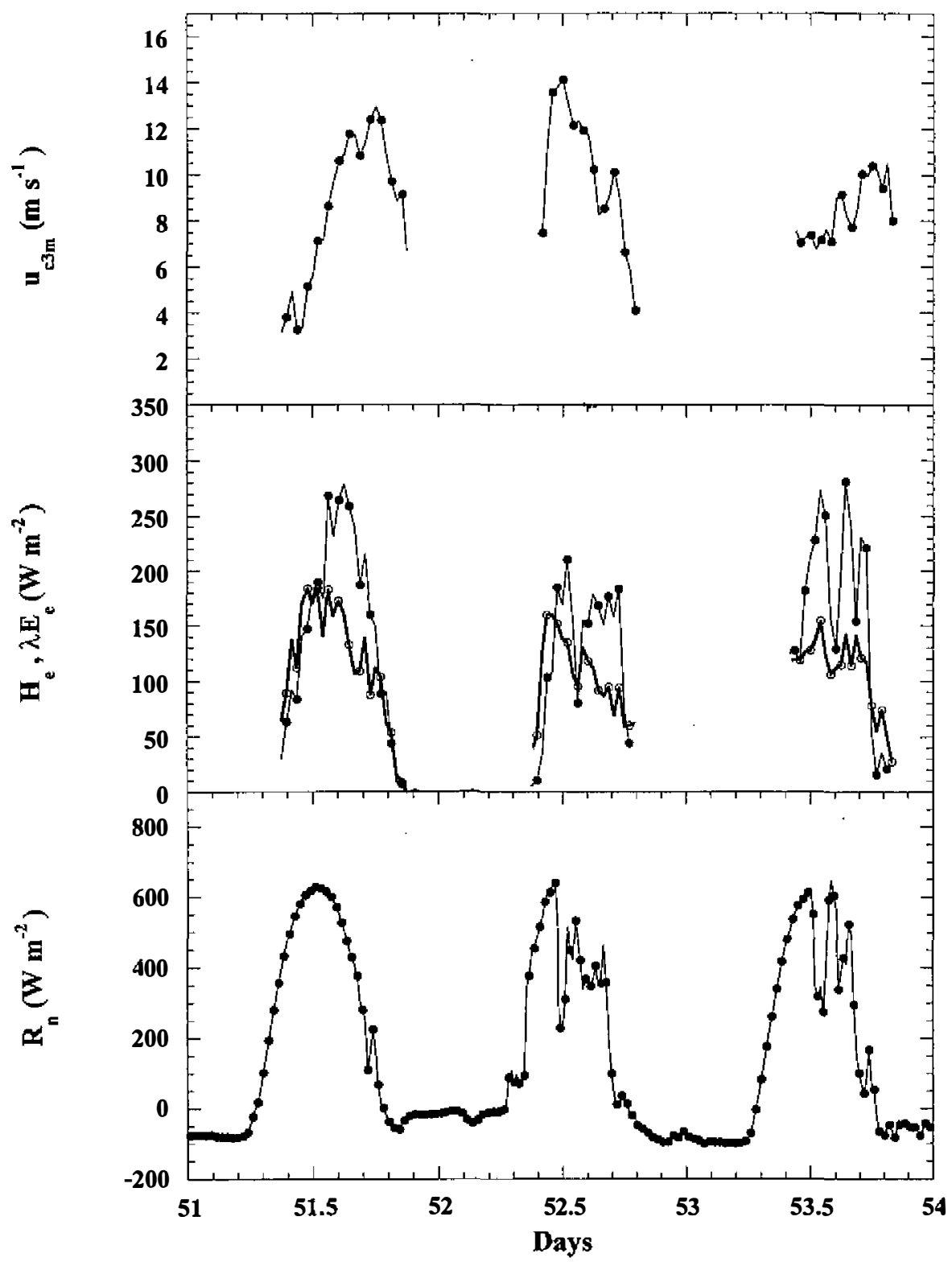

Fig. 2. Time series of eddy covariance determined fluxes $\mathrm{H}_{e}$ and $\lambda \mathrm{E}_{\mathrm{e}}$ along with net radiation, $\mathrm{Rn}$ and the average windspeed at $z=3 \mathrm{~m}, \mathrm{u}_{\mathrm{c} 3 \mathrm{~m}}$ for near neutral days D51, D52 and D53. 
Over the days D51, D52 and D53 and during daytime periods of high windspeed $\left(\mathrm{u}_{\mathrm{c} 3 \mathrm{~m}}>8\right.$ $\mathrm{ms}^{-1}$ ) both the microwave and near-infrared scintillometer signals had very large signal variances. Values of $\lambda \mathrm{E}_{\mathrm{s}}$ were at least an order of magnitude greater than $\lambda \mathrm{E}_{\mathrm{e}}$. The eddy covariance values of $H_{e}$ and $\lambda E_{e}$ are credible (Fig. 2). Figure 3 compares the two methods for halfhour averages of $\lambda^{e} \mathrm{E}$ selected over these three days. The 20:1 line offers a coarse indication of the disparity between the two methods.

The fluctuations measured by the scintillometer can not be due to the surface fluxes alone. The origin of these additional perturbations must lie elsewhere and were somehow related to the high wind-speeds at the scintillometer beam height $\left(\mathrm{u}_{\mathrm{c}}>20 \mathrm{~m} \mathrm{~s}^{-1}\right)$. There is the effect of the terrain to consider, as several kilometers upwind of the well-irrigated vineyard valley the landscape is mainly dry pasture and scrub. This situation describes a transition from dry to wet surfaces effectively the strong advection of dry air into the well-irrigated valley. De Bruin et al. (1991) and De Bruin et al. (1993) made a study of surface fluxes over non-uniform terrain under advective conditions, using both the variance and eddy covariance techniques and found $\mathrm{H}$ to be significantly overestimated using the former method. These extra temperature fluctuations were attributed to the entrainment of the upwind dry and warm air into the newly formed internal moist boundary layer (De Bruin, pers comms.) This is a plausible explanation for the observed increased variance in the scintillometer signals. However, because the scintillometer can not differentiate or seperate the source of this increased scintillation the derivation of $\mathrm{C}_{\mathrm{T}}^{2}$ and $\mathrm{C}_{\mathrm{Q}}^{2}$ is invalid and the scintillation method is flawed.

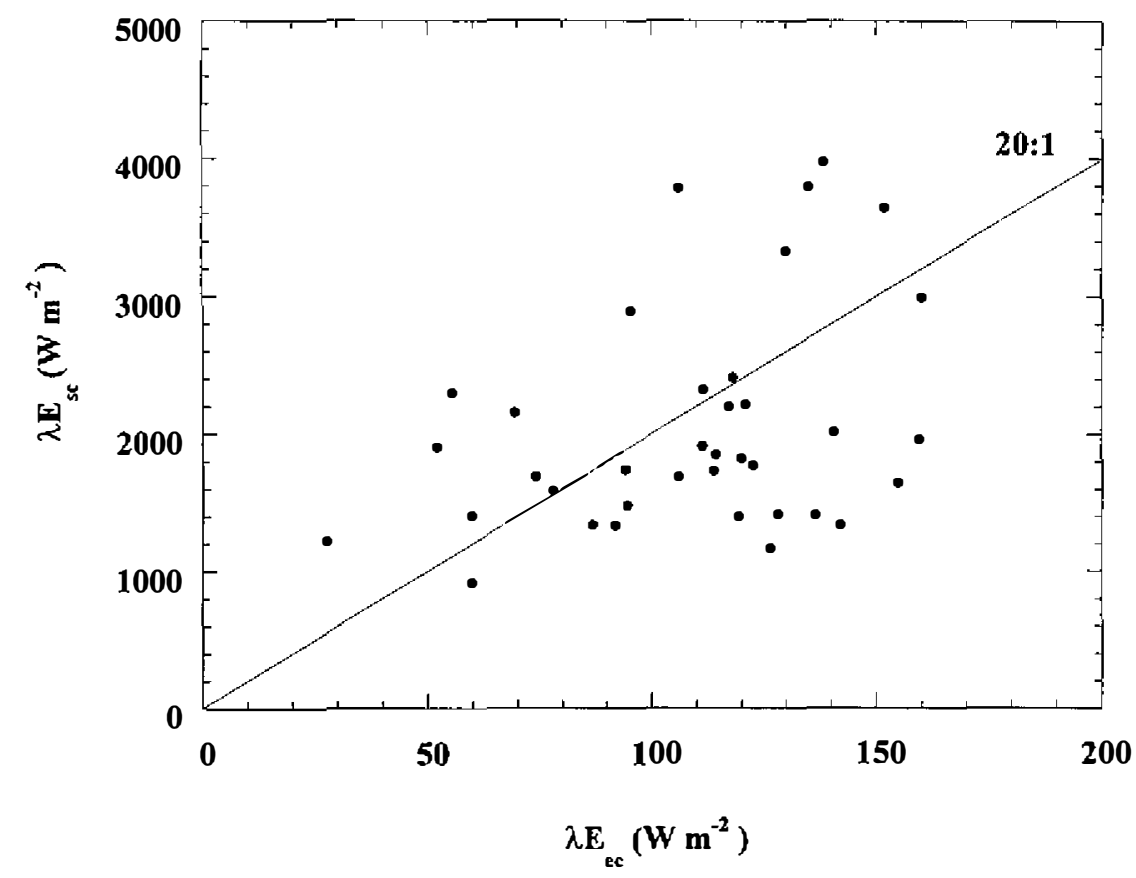

Fig. 3. A comparison of half hour averages of $\lambda \mathrm{E}_{\mathrm{s}}$ and $\lambda \mathrm{E}_{\mathrm{e}}$ obtained under near-neutral and strongly advective conditions. 
Also contributing to the additional signal variance may be wind turbulence generated by the valley slopes and the ridges where the scintillometers are positioned. Although the scintillometer path weighting is minimal at the transect extremes (Wang et al., 1978), additional mixing of the atmosphere by these physical barriers could have created unwanted fluctuations in $\mathrm{T}$ and $\mathrm{Q}$ within the valley. It is expected this effect would be particularly evident at the ridge height rather than near the valley floor as the wind accelerates upwards towards the crest of the hillsides (Kaimal and Finnigan, 1994). For the N-NW wind direction this meant the wind would strike the eastern ridge at an angle of approximately 45 degrees. The scintillometer data collected at height and under the combination of very strong advective $\mathrm{N}$ - NW winds taking place within this valley, remains unusable in its present form.

\subsection{Unstable Conditions}

Constant heavy rain over days D54 and D55 meant all instrumentation had been turned off during this period to protect against failure. The experiment was restarted at $0900 \mathrm{hrs}$ on day D56. As Fig. 4 shows, the morning of day D56 was characterised by a clear sky and air temperature around $12^{\circ} \mathrm{C}$. $\mathrm{R}_{\mathrm{n}}$ steadily increased to a $700 \mathrm{~W} \mathrm{~m}^{-2}$ maximum at $1230 \mathrm{hrs}$ followed by intermittent cloud cover over the afternoon. Light SW winds $\left(\mathrm{u}_{\mathrm{cmm}} \sim 4 \mathrm{~m} \mathrm{~s}^{-1}\right)$ passed through the scintillometer beam but after midday the wind began to shift direction rotating 180 degrees towards the NE. Over the next 3 hours as the wind increased in speed to $\left(\mathrm{u}_{\mathrm{c} 3 \mathrm{~m}} \sim 7.5 \mathrm{~m}\right.$ $\left.\mathrm{s}^{-1}, 1500 \mathrm{hrs}\right)$ it blew first EW down the scintillometer beam before finally settling into a NE direction ( $1500 \mathrm{hrs})$. A time trace of daily half hourly averaged values of $\lambda \mathrm{E}_{\mathrm{s}}$ and $\lambda \mathrm{E}_{\mathrm{e}}$ is presented in Fig. 5. The transition in wind direction during this period has been indicated on Fig. 5 using the notation, SW, EW and NE.

Until $1200 \mathrm{hrs}$ (SW wind) the comparison between $\lambda \mathrm{E}_{\mathrm{s}}$ and $\lambda \mathrm{E}_{\mathrm{e}}$ was reasonable. In the afternoon when the wind shifted direction to the EW to blow over the east-ridge and down the scintillometer beam there was a marked underestimation by $\lambda \mathrm{E}_{\mathrm{s}}$. On several occasions during the early afternoon transition in wind shift the structure parameter $C_{T}^{2}$ was observed to vary by more than an order of magnitude over 10 minute periods. Following Hill et al. (1992) we have classified these periods as non-stationary. The atmospheric conditions prevented the application of MOST. By mid afternoon ( $1500 \mathrm{hrs})$ agreement between $\lambda \mathrm{E}_{\mathrm{s}}$ and $\lambda \mathrm{E}_{\mathrm{e}}$ had improved. Drier winds that blew from the NE apparently advected sufficient dry air into the valley so there was a trend for $\lambda \mathrm{E}_{s}>\lambda \mathrm{E}_{e}$.

The $\mathrm{D} 56$ behaviour of $\lambda \mathrm{E}_{\mathrm{sc}}$ can be demarcated roughly into three temporal transitions caused by a 180 degree change in wind direction. The results suggest the successful comparison of the scintillometer and eddy covariance methods is dependent on the strength and the direction of the wind, the surrounding topography and their relation to the scintillometer beam orientation.

During the morning of day D57 the atmosphere tended towards highly unstable conditions to provide a data set with which to test the effectiveness of (2.11). Average wind-speed was low during the first part of the day $\left(\mathrm{u}_{\mathrm{c} 3 \mathrm{~m}}<1.5 \mathrm{~m} \mathrm{~s}^{-1}\right)$ and the sky was clear throughout the previous night and extended over the morning of D57 (Fig. 6). By noon the air temperature had climbed to $19^{\circ} \mathrm{C}$ from an early morning low of $10^{\circ} \mathrm{C}(0800 \mathrm{hrs})$. From noon the wind- 


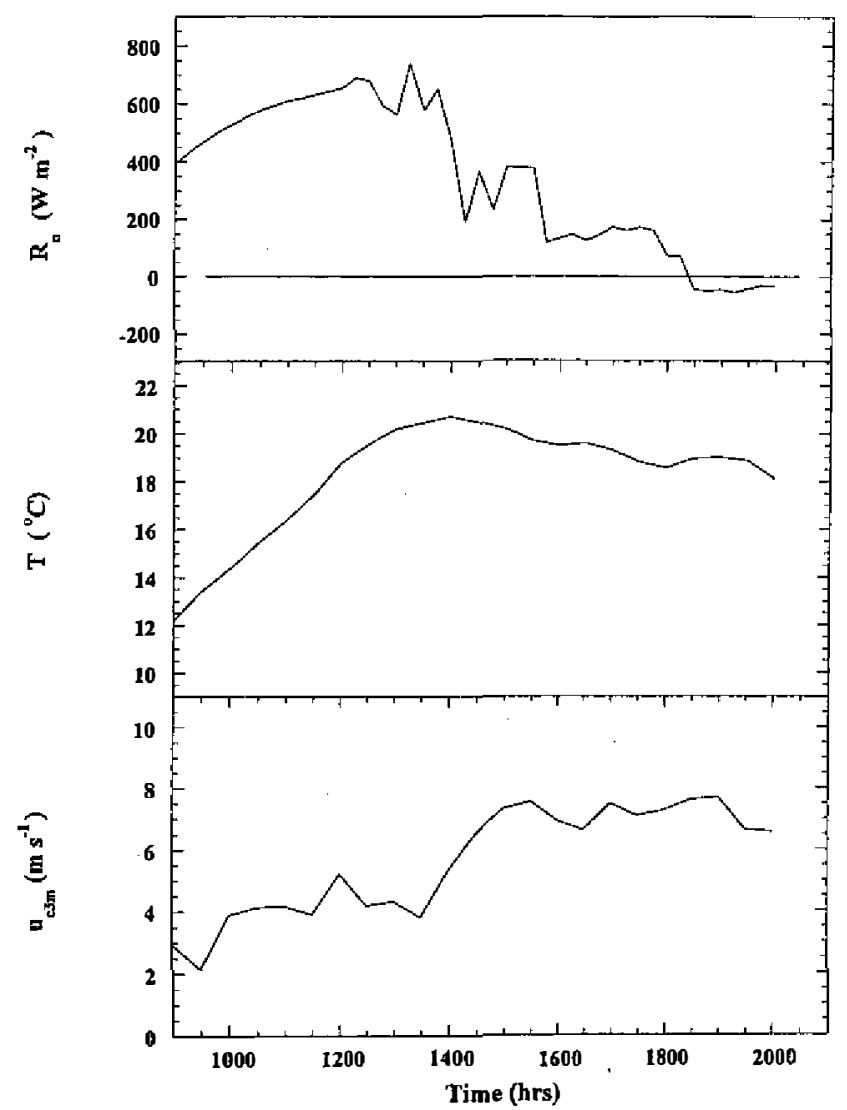

Fig. 4. Average wind-speed at $\mathrm{z}=$ $3 \mathrm{~m}, \mathrm{u}_{\mathrm{c} 3 \mathrm{~m}}$ and net radiation $\mathrm{R}_{\mathrm{n}}$ during the unstable conditions of day, D56.

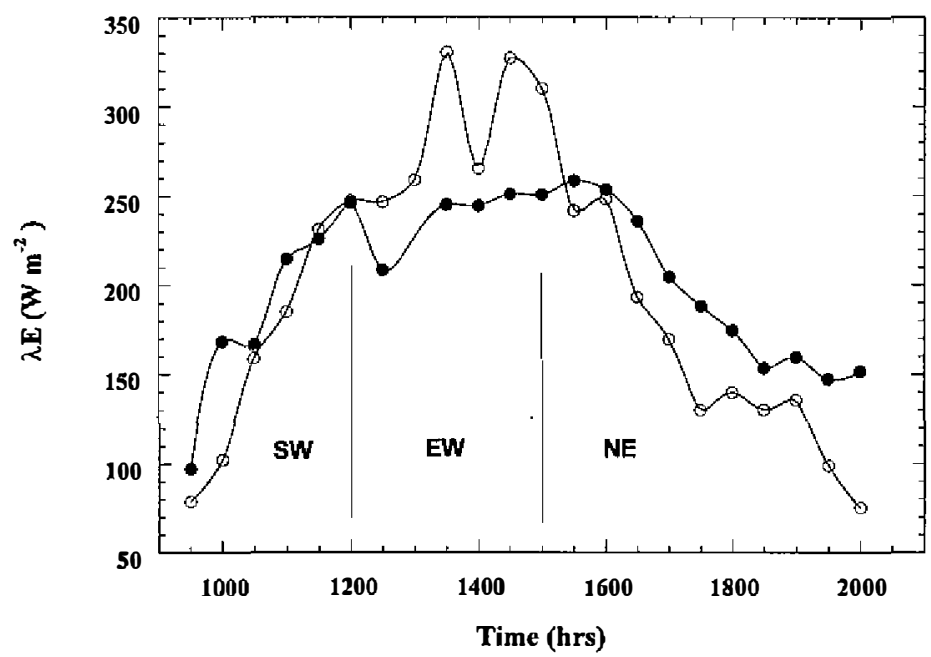

Fig. 5. A time series of $\lambda \mathrm{E}_{\mathrm{s}}(\bullet)$ and $\lambda \mathrm{E}_{\mathrm{e}}(\mathrm{o})$ for D56, a day of unstable atmospheric conditions with shifting wind direction. 
speed increased from $\mathrm{u}_{\mathrm{c} 3 \mathrm{~m}} \sim 2 \mathrm{~m} \mathrm{~s}^{-1}$ to $\mathrm{u}_{\mathrm{c} 3 \mathrm{~m}} \sim 7 \mathrm{~m} \mathrm{~s}^{-1}$ by $1600 \mathrm{hrs}$ and from a northerly direction. As significant mechanical mixing was now occurring in the boundary layer (2.11) was no longer valid.

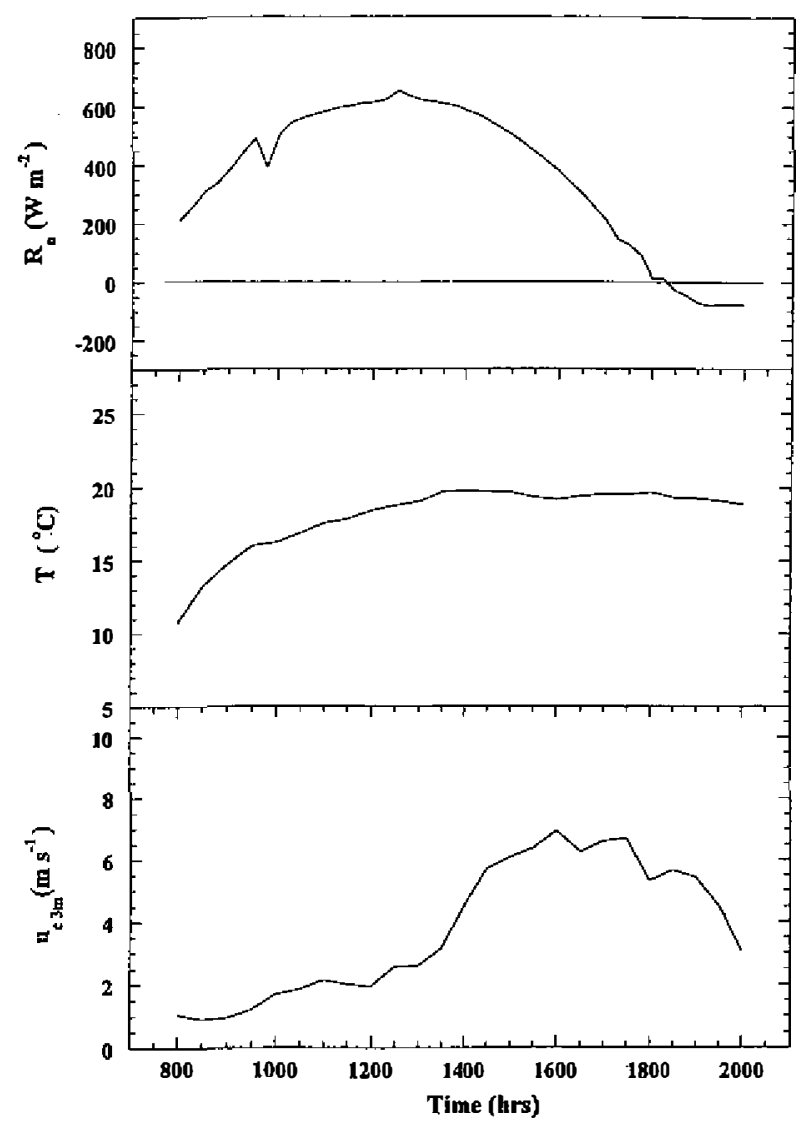

Fig. 6. Air temperature, $\mathrm{T}$, average wind-speed at $\mathrm{z}=3 \mathrm{~m}, \mathrm{u}_{\mathrm{c} 3 \mathrm{~m}}$ and net radiation, $R_{n}$ for day, D57 which experienced very unstable conditions in the morning period.

Figure 7 is a time series comparison between $\lambda E_{s}$ and $\lambda E_{e}$ for D57. In the period between 0800 and $1330 \mathrm{hrs} \lambda \mathrm{E}_{\mathrm{s}}$ was been calculated using (2.11) assuming very unstable conditions. From $1400 \mathrm{hrs}$ onwards and with the increasing wind-speed, $\lambda \mathrm{E}_{\mathrm{s}}$ is determined using the iterative method as described for unstable conditions. In the first instance and in contrast to $\lambda E_{e}$, the values of $\lambda E_{s}$ lying between 0800 and $1030 \mathrm{hrs}$ are larger than believable as $R_{n}<$ $450 \mathrm{~W} \mathrm{~m}^{-2}$.

During this period the values of $\mathrm{C}_{\mathrm{T}}^{2}$ and $\mathrm{C}_{\mathrm{Q}}^{2}$ (Fig. 8) experienced an increase in magnitude peaking at $0900 \mathrm{hrs}$. Calculated $\lambda \mathrm{E}_{\mathrm{s}}$ was then very much greater than expected from a surface latent heat flux. Both the microwave and large aperture infrared scintillometer signals independently showed additional signal variance. In explanation it is proposed these peaks 


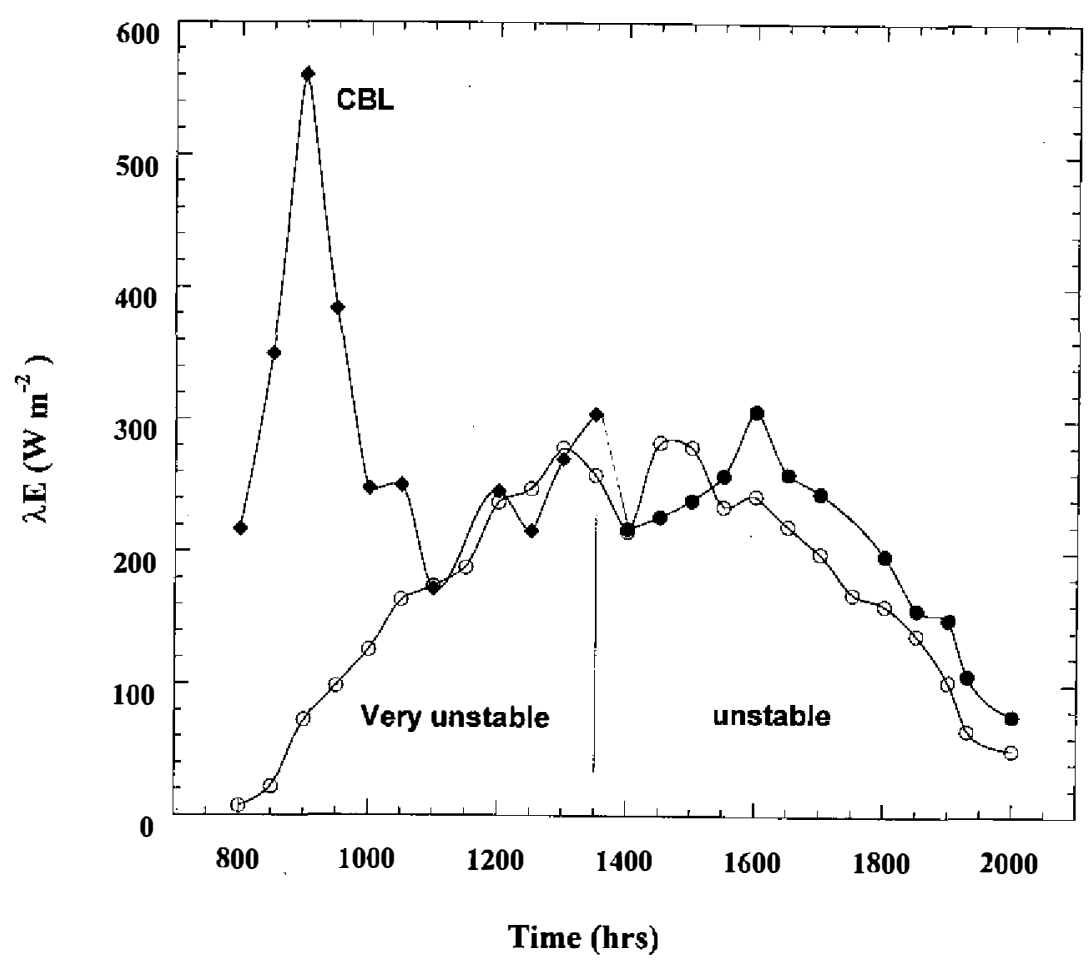

Fig. 7. A time series for day D57 showing the effect of the CBL passing through the scintillometer beam mid-morning and the reasonable agreement obtained between very unstable $\lambda \mathrm{E}_{\mathrm{s}}(\bullet)$ and unstable $\lambda \mathrm{E}_{\mathrm{s}}(\bullet)$ with values of $\lambda E_{e}(0)$.

are indicative of the evolution of the CBL (as indicated on Fig. 7) growing in height in response to surface heating. Stull (1988) describes the depth of the CBL increasing slowly, under calm situations, from several tens of metres controlled by the strong nocturnal stable layer capping the CBL. We believe that as the air temperature rose in the mid-moming, the top of the CBL moved upward and passed through the scintillometer beam. The transition in air density as the warmer air moved through the beam caused additional fluctuations to be recorded by the scintillometer, but these went unseen by the eddy covariance instruments. Kohsiek and Herben (1983) infer this behaviour in their paper when describing evaporation made by measurements of radio wave scintillation. Additionally, Wyngaard and LeMone (1980) discuss the behaviour of $\mathrm{C}_{\mathrm{T}}^{2}$ and $\mathrm{C}_{\mathrm{Q}}^{2}$ in the CBL and observed that these values can be several orders of magnitude greater near the inversion height than expected through that generated by surface fluxes.

By late morning ( $1100 \mathrm{hrs}$ ) the height of the CBL had grown beyond both the scintillometer and eddy covariance instruments and the fluxes recorded by both instruments was contained within the convective surface layer. Application of (2.11) for free convective conditions was valid and demonstrated extremely pleasing agreement between $\lambda \mathrm{E}_{\mathrm{s}}$ and $\lambda \mathrm{E}_{\mathrm{e}}$ from 1100 to $1330 \mathrm{hrs}$ (Fig. 7). At $1130 \mathrm{hrs}$ an acrylic screen was placed over the scintillometer 


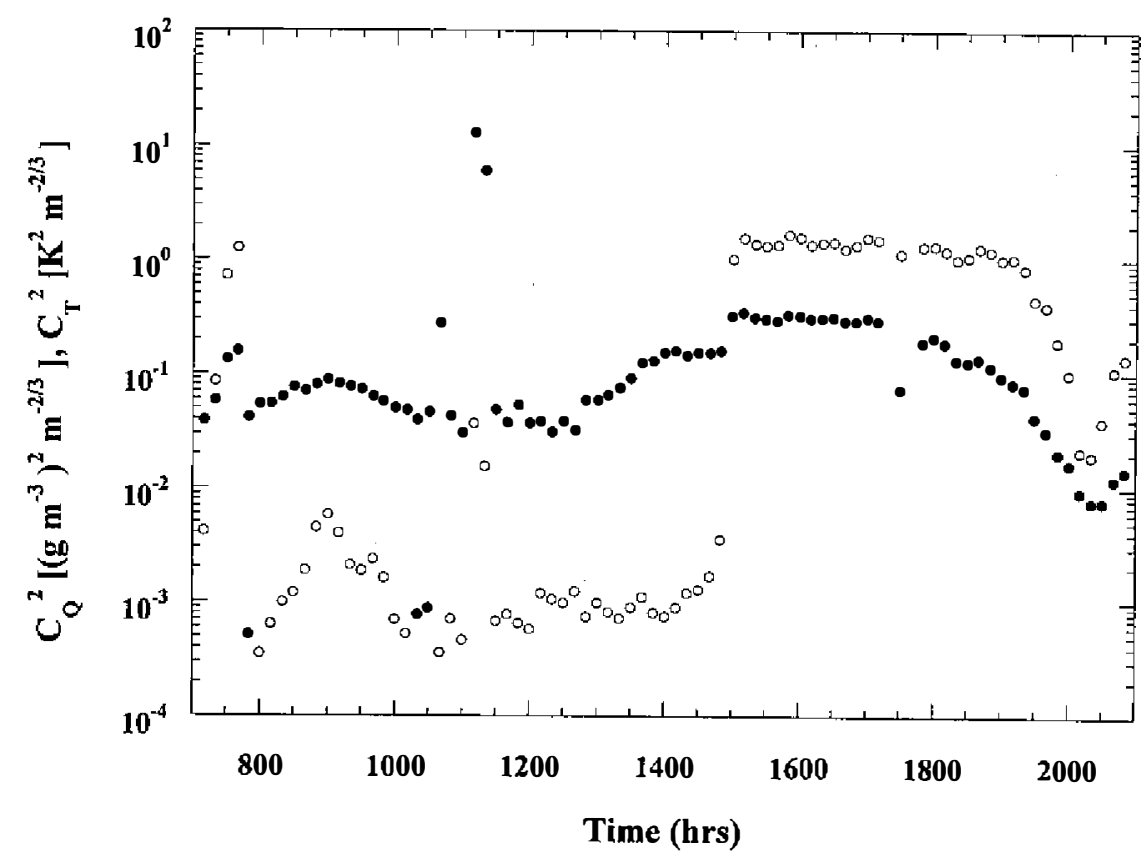

Fig. 8. The behaviour of the structure parameters $\mathrm{C}_{\mathrm{T}}^{2}(\mathrm{o})$ and $\mathrm{C}_{\mathrm{Q}}^{2}(\bullet)$ for day, D57. Each of the spikes in the time races are periods when reliable data is unavailable. This is due either to obstruction of the beam or the behaviour of the atmosphere as it undergoes various transitions.

transmitter. A similar screen was erected at the scintillometer receiver about $1730 \mathrm{hrs}$. The screens were designed to prevent mechanical oscillations by heavy winds moving the scintillometers. This modification to the enclosures caused peaks in $\mathrm{C}_{\mathrm{T}}^{2}$ and $\mathrm{C}_{\mathrm{Q}}^{2}$ about 1130 and $1730 \mathrm{hrs} \mathrm{(Fig.} \mathrm{8)} \mathrm{as} \mathrm{the} \mathrm{scintillometer} \mathrm{beam} \mathrm{was} \mathrm{broken.} \mathrm{There} \mathrm{is} \mathrm{no} \mathrm{evidence} \mathrm{there} \mathrm{was} \mathrm{an}$ improvement in the scintillometers performance by the placement of these screens. From 1400 hrs onwards the free convective formula was discarded in favour of the unstable approach. Calculations of $\lambda \mathrm{E}_{\mathrm{s}}$ constantly overestimate $\lambda \mathrm{E}_{\mathrm{e}}$ in a manner similar to the results of day, D56. The sudden jump in magnitude of both $\mathrm{C}_{\mathrm{T}}^{2}$ and $\mathrm{C}_{\mathrm{Q}}^{2}$ around $1430 \mathrm{hrs}$ (Fig. 8) from one plateau to another occurs with increased wind-speed (see $u_{c 3 m}$, Fig. 7).

During the very unstable conditions the signal from the near-infrared scintillometer was very close to the insument noise. Some discussion on this problem is warranted because the scintillation method relies on accurate measurements of $C_{n, i}^{2}$. During very unstable conditions simple theory states that both $\mathrm{C}_{\mathrm{T}}^{2}$ and $\mathrm{C}_{\mathrm{Q}}^{2}$ are proportional to $z^{-4 / 3}$ within the surface boundary layer. In practical terms this means the magnitude of $\mathrm{C}_{\mathrm{T}}^{2}$ or $\mathrm{C}_{\mathrm{Q}}^{2}$ measured by a scintillometer placed at a height of $\mathrm{z}=30 \mathrm{~m}$ will be only $5 \%$ of that measured by the same instrument placed at $z=3 \mathrm{~m}$ above the valley floor. This reduction in signal sength becomes problematic for low values of evaporation as the scintillometers must be capable of a suitable signal resolution without approaching their own noise limit. During the convective conditions, $\mathrm{C}_{\mathrm{T}}^{2}$ was three orders of magnitude less than the values measured over the unstable mid- 
afternoon situation (Fig. 8). The other two peaks in $\mathrm{C}_{\mathrm{T}}^{2}$ and $\mathrm{C}_{\mathrm{Q}}^{2}$ occurring in the early morning and the early evening ( $0700-0800 \mathrm{hrs}$ and $2000-2100 \mathrm{hrs})$ represent the transition between the unstable and stable atmospheric states. During these periods $\mathrm{C}_{\mathrm{T}}^{2}$ and $\mathrm{C}_{\mathrm{Q}}^{2}$ are indeterminable as will be $\lambda \mathrm{E}_{\mathrm{s}}$.

The final days of the experiment, D58 and D59, are not discussed in detail here as both were overcast, cold and with strong winds blowing NW down the scintillometer transect making data interpretation difficult. During this period the signal output from the infrared scintillometer was observed to approach its own noise limit $\left(\mathrm{C}_{\mathrm{n}}^{2}<10^{-17} \mathrm{~m}^{-2 / 3}\right)$. However the clear early morning of day, D58, provided several half-hour data points which although not presented had $\lambda \mathrm{E}_{\mathrm{s}}$ and $\lambda \mathrm{E}_{\mathrm{e}}$ in close agreement.

The issue of improving the signal strength of the near-infrared scintillometer is currently being addressed through the use of a more powerful radiation source. It is noted the microwave scintillometer signal strength was always adequate.

\section{CONCLUSION}

The purpose of this research was to identify whether the scintillometer method could be used to estimate evaporation from a vineyard valley to be capable of providing figures for daily irrigation scheduling and the management of water resources. The scintillometer was placed on opposing valley ridges to propagate its beam across and well above the valley floor. In calculating $\lambda \mathrm{E}_{\mathrm{s}}$ it was assumed that similarity theory was workable in the valley and the scintillations were caused by the surface fluxes of heat and moisture.

The results demonstrate the success of these $\lambda \mathrm{E}_{\mathrm{s}}$ measurements when compared with eddy covariance data are dependent on prevailing atmospheric conditions and the surrounding terrain. Operating scintillometers at $\mathrm{z}=30 \mathrm{~m}$ creates additional problems not encountered when the beam is closer to the canopy. These problems are extraordinary scintillations and much weaker signals whose symptoms are an excessive intensity variance and reduced signalto-noise ratio. The cases identified to date include the entrainment of warm dry air under advective conditions and the development of the $\mathrm{CBL}$ as it passes through the scintillometer beam. Confirmation of these phenomena is a next experimental step. Excessive wind-speed contributed to the overestimation of $\lambda \mathrm{E}_{\mathrm{s}}$ relative to $\lambda \mathrm{E}_{\mathrm{e}}$ during unstable conditions. The difference became extreme for near-neutral conditions with a dry to wet ransition downwind. There is no evidence to suggest the scintillometer combination will not perform well when operated at this height and under near-neutral conditions over uniform terrain. The free convection formula gave good results for the small data set collected.

In summary the results presented indicate the scintillation method can produce credible estimations of $\lambda \mathrm{E}_{\mathrm{s}}$ from an irrigated valley. The scintillometer performed best under unstable to very unstable atmospheric conditions. The reasonable comparison between the scintillometer and eddy covariance time series suggests the application of similarity theory was appropriate. Scintillometers need to be mounted at greater heights than conventional instruments in order to obtain an unobstructed propagation of their beams across kilometer distances and to compensate for curvature of the Earth. As a result they may encounter some of the unwanted 
effects reported in this experiment.

Acknowledgments We wish to express our gratitude to Tony Hoksbergen, National Viticulturist, Montana Wines Ltd., Blenheim for use of the facilities at the Brancott Estate. Our thanks go to the staff at the Malborough Research Centre who were most helpful in organising the accommodation, transport and general logistics for the personal involved in the experiment. Brent Clothier suggested the site and was instrumental in negotiating the use of the vineyard with Montana Wines. Philip Prendergast, Keith McNaughton and Johannes Laubach are thanked for their assistance in setting up instrumentation. Unfortunately separate eddy covariance measurements made by Laubach during this experiment were too fragmented to be of any practical use in our analysis. We thank staff at the Marlborough District Council for contacting the local landowners for site access and their interest in this research. Wim Kohsiek and Henk De Bruin are thanked for their useful comments and suggestions on this manuscript.

\section{REFERENCES}

De Bruin, H. A. R., N. J. Bink, and L. J. M. Kroon, 1991: Land Surface Evaporation. Fluxes in the Surface Layer Under Advective Conditions. In: Schmugge and Andre (Eds.), Springer-Verlag, New York.

De Bruin, H. A. R., W. Kohsiek, and B. J. J. M. van den Hurk, 1993: A verification of some methods to determine the fluxes of momentum, sensible heat, and water vapour using standard deviation and structure parameter of scalar meteorological quantities. Boundary-Layer Meteorol, 63, 231-257.

De Bruin, H. A. R., B. J. J. M. van den Hurk, and W. Kohsiek, 1995: The scintillation method tested over a dry vineyard area. Boundary-Layer Meteorol, 76, 25-40.

Green, A. E., M. S. Astill, K. J. McAneney, and J. P. Nieveen, 1999: Path-averaged surface fluxes determined from infrared and microwave scintillometers. Submitted Ag. and Forest Meteorol.

Hill, R. J., S. F. Clifford, and R. S. Lawerence, 1980: Refractive-index and absorption fluctuations in the infrared caused by temperature, humidity and pressure fluctuations. $J$. Opt. Soc. Am., 70, 1192-1205.

Hill, R. J., R. A. Bolander, S. F. Clifford, R. W. McMillan, J. T. Priestley, and W. P. Schofield, 1988: Turbulence-induced millimetre-wave scintillation compared with micrometeorological measurements. IEEE Trans. On Geosci. and Remote Sensing, 26, 330-341.

Hill, R. J., 1989: Implications of Monin-Obukhov similarity theory for scalar quantities. $J$. Atmos. Sci. 46, 2235-2244.

Hill, R. J., G. R. Ochs, and J. J. Wilson, 1992: Measuring surface-layer fluxes of heat and momentum using optical scintillation. Boundary-Layer Meteorol., 58, 391-408.

Kaimal, J. C., and J. J. Finnigan, 1994: Atmospheric Boundary Layer Flows: Their Structure and Measurement. Oxford University Press Inc., New York.

Kohsiek, W., 1982: Measuring $\mathrm{C}_{\mathrm{T}}^{2}, \mathrm{C}_{\mathrm{Q}}^{2}$, and $\mathrm{C}_{\mathrm{TO}}$ in the unstable surface layer, and relation to the vertical fluxes of heat and moisture. Boundary-Layer Meteorol, 24, 89-107. 
Kohsiek, W., 1985: A comparison between line-averaged observation of $C_{n}^{2}$ from scintillation of a laser beam and time-averaged in situ observations. J. Climate and Appl. Meteorol., 24, 1099-1102.

Kohsiek, W., and M. H. A. J. Herben, 1983: Evaporation derived from optical and radio wave scintillation. J. Appl. Opt., 22, 629-633.

Panofsky, H. A., and J. A. Dutton, 1984: Atmospheric Turbulence. Models and Methods for Engineering Applications. John Wiley and Sons, New York.

Sene, K. J., 1994: Parameterizations for energy transfers from a sparse vine crop. Ag. and Forest Meteorol., 71, 1-18.

Stull, R. B., 1988: An Introduction to Boundary Layer Meteorology. Kluwer Academic Publishers, The Netherlands.

Wang, Ting-I, G. R. Ochs, and S. F. Clifford, 1978: A saturation-resistant optical scintillometer to measure $\mathrm{C}_{\mathrm{n}}^{2}$.J. Opt. Soc. Am., 68, 334-338.

Wyngaard, J. C., 1973: On surface-layer turbulence. Workshop on Micrometeorology. In: D. A. Haugen (Ed.), Amer. Meteorol. Soc., 101-149.

Wyngaard, J. C, and M. A. LeMone, 1980: Behaviour of the refractive-index structure parameter in the entraining convective boundary layer. J. Atm. Sci., 37, 1573-1585. 